\title{
Acoustically Responsive Fibers in the Vestibular Nerve of the Cat
}

\author{
Michael P. McCue 1,2,a and John J. Guinan, Jr. 1,2,3,4 \\ 'Eaton-Peabody Laboratory of Auditory Physiology, Department of Otolaryngology, Massachusetts Eye and Ear Infirmary, \\ Boston, Massachusetts 02114, ${ }^{2}$ Harvard-MIT Division of Health Science and Technology and Research Laboratory of \\ Electronics, and ${ }^{3}$ Department of Electrical Engineering and Computer Science, Massachusetts Institute of Technology, \\ Cambridge, Massachusetts 02139, and 4Department of Otology and Laryngology, Harvard Medical School, Boston, \\ Massachusetts 02115
}

Recordings were made from single afferent fibers in the inferior vestibular nerve, which innervates the saccule and posterior semicircular canal. A substantial portion of the fibers with irregular background activity increased their firing in response to moderately intense clicks and tones.

In responsive fibers, acoustic clicks evoked action potentials with minimum latencies of $\leq 1.0 \mathrm{msec}$. Fibers fell into two classes, with the shortest latency either to condensation clicks (PUSH fibers) or to rarefaction clicks (PULL fibers). Low-frequency $(800 \mathrm{~Hz})$ tone bursts at moderately high sound levels ( $>80 \mathrm{~dB}$ SPL) caused synchronization of spikes to preferred phases of the tone cycle. PUSH and PULL fibers had preferred response phases approximately $180^{\circ}$ apart. These two response classes are consistent with fibers that innervate hair cells having opposite morphological polarizations, an arrangement found in the saccule.

With low-frequency tone bursts, sound levels of $\geq 90 \mathrm{~dB}$ SPL evoked increases in mean spike rate. Spike rates increased monotonically with sound level without saturating at levels $\leq 115 \mathrm{~dB}$ SPL. Contraction of the middle-ear muscles decreased responses to sound, consistent with the sound transmission path being through the middle ear.

Several fibers were labeled with biocytin and traced. All labeled fibers had bipolar cell bodies in the inferior vestibular ganglion with peripheral processes extending toward the saccular nerve and central processes in the vestibular nerve. Two fibers were traced to the saccular epithelium. One fiber was traced centrally and arborized extensively in vestibular nuclei and a region ventromedial to the cochlear nucleus.

Our results confirm and extend previous suggestions that the mammalian saccule responds to sound at frequencies

Received Nov. 1, 1993; revised Mar. 15, 1994; accepted Apr. 6, 1994.

This work was submitted by M.P.M. to the Harvard-M.I.T. Division of Health Sciences and Technology in partial fulfillment of the requirements for the Sc.D. degree at the Massachusetts Institute of Technology and the M.D. degree at Harvard Medical School. We thank Drs. W. T. Peake, D. P. Corey, and N. Y.-S. Kiang for advice, manuscript comments, and criticism. Assistance in surgery was provided by L. W. Dodds, K. Jacob, and T. S. Liu, in engineering by F. Cardarelli, and in histology and fiber construction by B. E. Norris. This research was partially supported by a grant from the Johnson and Johnson Company, and by NIH Grant R01 DC 00235. M.P.M. received support from NIH Training Grant T32 DC 00006 , Fairchild Foundation, and the Fulbright Commission.

Correspondence should be addressed to John J. Guinan, Jr., Eaton-Peabody Laboratory of Auditory Physiology, Massachusetts Eye and Ear Infirmary, 243 Charles Street, Boston, MA 02114.

"Present address: Department of Surgery, Massachusetts General Hospital, Boston, MA 02114

Copyright (C) 1994 Society for Neuroscience $0270-6474 / 94 / 146058-13 \$ 05.00 / 0$ and levels within the normal range of human hearing. We suggest a number of auditory roles that these fibers may play in the everyday life of mammals.

[Key words: saccule, otoliths, auditory system, mammalian sound reception, middle-ear muscles, cochlear nucleus]

The vertebrate inner ear contains several sense organs involved in the maintenance of equilibrium and the detection of vibration. The precise sensory role assumed by homologous organs varies among species. For example, the saccule is thought to act as a linear accelerometer in mammals (Fernández and Goldberg, $1976 \mathrm{a}-\mathrm{c})$ but is responsive to sound in amphibians, fishes, and rays (Lowenstein and Roberts, 1951; Popper and Fay, 1973; Moffat and Capranica, 1976; Lewis et al., 1982; Saidel and Popper, 1983).

Whether any of the mammalian vestibular organs plays a role in normal hearing is an open question that hinges on two factors - the acoustic sensitivity of the rcceptors and the central processing of their outputs. The normal acoustic sensitivity of the vestibular receptors has been controversial. Young et al. (1977) sampled primary vestibular afferents from all of the vestibular organs in the squirrel monkey and found that, in response to intense sounds, many fibers fired preferentially during one sound phase. However, increases in mean discharge rate were not observed in most fibers until the sound reached levels associated with rapid cochlear damage ( $>120 \mathrm{~dB}$ SPL). This study, which demonstrated acoustic responsiveness yet emphasized high thresholds, has been cited as evidence both for (Cazals et al., 1980) and against (Kevetter and Perachio, 1989) a hearing role for the mammalian vestibular system.

Even if a class of vestibular nerve fibers responds to sound, these acoustic responses might be of no benefit (and potentially of some harm) if they are not processed centrally as auditory information. The recent demonstrations of mammalian primary vestibular afferents that send projections into the cochlear nucleus (Burian and Gstoettner, 1988; Kevetter and Perachio, 1989) might provide the necessary connection for some vestibular afferents to have a role in hearing.

We have recently found a class of mammalian primary vestibular afferents with properties that possibly indicate that they are involved in normal hearing. We present here anatomical and physiological evidence indicating (1) that these afferents originate in the saccule, (2) that they are excited by acoustic stimuli at moderately high sound levels, and (3) that these acoustic stimuli reach the inner ear via normal middle-ear transmis- 
sion and activate the vestibular afferents by normal hair-cell stimulation.

A preliminary report of this work has been presented (McCuc and Guinan, 1993).

\section{Materials and Methods}

Surgery. Treatment of experimental animals was in accordance with protocols approved by the Committees on Animal Care at the Massachusetts Institute of Technology and the Massachusetts Eye and Ear Infirmary. Adult cats were induced and maintained under anesthesia by intraperitoneal injection of diallyl barbituric acid in urethane (Kiang et al., 1965). A tracheostomy was performed. The ear canals were surgically exposed and the auditory bullae were opened. In some cats, the bony septum between the bulla and middle ear was removed and the tendons of the middle-ear muscles (stapedius and tensor tympani) were cut. A posterior fossa cranicctomy was pcrformed, and the cerebellum was aspirated laterally to expose the dorsal surface of the temporal bone. After reflection of the periosteum, the roof of the internal auditory meatus was drilled away with a dental burr to expose the junction of the inferior and superior vestibular nerves (Liberman and Brown, 1986). Extreme care was taken to maintain the structural integrity of the bony labyrinth.

Monitoring. Animals were placed in an electrically and acoustically shielded chamber (Ver et al., 1975). Rectal temperature was maintained at $36-39^{\circ} \mathrm{C}$ by adjustment of the chamber temperature. Pulse and respiration were continuously monitored, and artificial ventilation was supplied when needed. Silver-wire electrodes were placed in contact with the cochlea near the round window and used to monitor thresholds of the compound action potential of the auditory nerve $\left(\mathrm{N}_{1}\right)$ in response to tone pips at octave intervals in the range of $0.5-32 \mathrm{kHz}$. Threshold shifts of $\mathrm{N}_{1}$ were frequently noted after long periods of intense sound, but were not clearly associated with shifts in the acoustic response thresholds of vestibular afferents.

Sound stimulation. Sound was delivered through metal acoustic assemblies sealed against each tympanic ring (Kiang et al., 1965). The sound source was a 1 inch condenser earphone (Brüel and Kjaer 4132), which was fixed to the metal acoustic assembly. A 1/4 inch condenser microphone (Brüel and Kjaer 4135) was attached to a small metal probe tube ending near the tympanic membrane and was used to determine sound levels as a function of frequency. The maximum sound pressure level was $115 \mathrm{~dB}$ re $0.0002 \mathrm{dyn} / \mathrm{cm}^{2}$ (sound pressure level or SPL).

Sound stimulation and neural recording were done under computer control (Apple Macintosh Quadra 950) through two instrumentation buses (one GPIB, and one special-purpose bus connected via a highspeed digital I/O interface). Sound stimuli consisted of tone bursts or clicks. Tone burst voltage waveforms were generated by passing the output of a programmable oscillator (Hewlett-Packard 3325B) through an electronic switch (Wilsonics BSIT) with a $2.5 \mathrm{msec} \cos ^{2}$-shaped risefall time. Click voltage waveforms consisted of rectangular $100 \mu \mathrm{sec}$ pulses. Voltage waveforms were delivered to the acoustic system through programmable attenuators.

Analog recording. Cochlear response waveforms recorded near the round window were amplified and then digitized by a National Instruments NB-A2000.

Neural recording. Single-unit activity was obtained by impaling peripheral nerve fibers with glass micropipettes filled with $2 \mathrm{M} \mathrm{KCl}$ (impedances of $15-40 \mathrm{M} \Omega$ in saline). A remotely controlled microdrive (Kopf 607W) was used to advance the microelectrode in $3 \mu \mathrm{m}$ steps. All recordings were made in the region of the inferior vestibular nerve near its junction with the superior vestibular nerve (Fig. 1). Action potentials were amplified, bandpass filtered, and transformed to discrete pulses by a Schmitt trigger. Spike pulses, stimulus markers, and positivegoing zero crossings of the tone voltage waveforms were measured with microsecond accuracy by a special-purpose event timer and periodically downloaded to the computer for the construction of histograms.

Measurement protocol. Spike discharges were fed to a speaker for audio monitoring. Units were detected by a drop in the recorded DC potential or the onset of spontaneous activity. When a new unit was detected, it was tested with $800 \mathrm{~Hz}$ tone bursts at $115 \mathrm{~dB}$ SPL. Units that displayed audible increases in discharge rate to this stimulus were classified as acoustically responsive and studied further with a relatively standard measurement protocol. First, an isoresponse measurement ("tuning curve") was taken for frequencies between $50 \mathrm{kHz}$ and $100 \mathrm{~Hz}$ (as described in McCue, 1993), followed by a $20 \mathrm{sec}$ measurement of

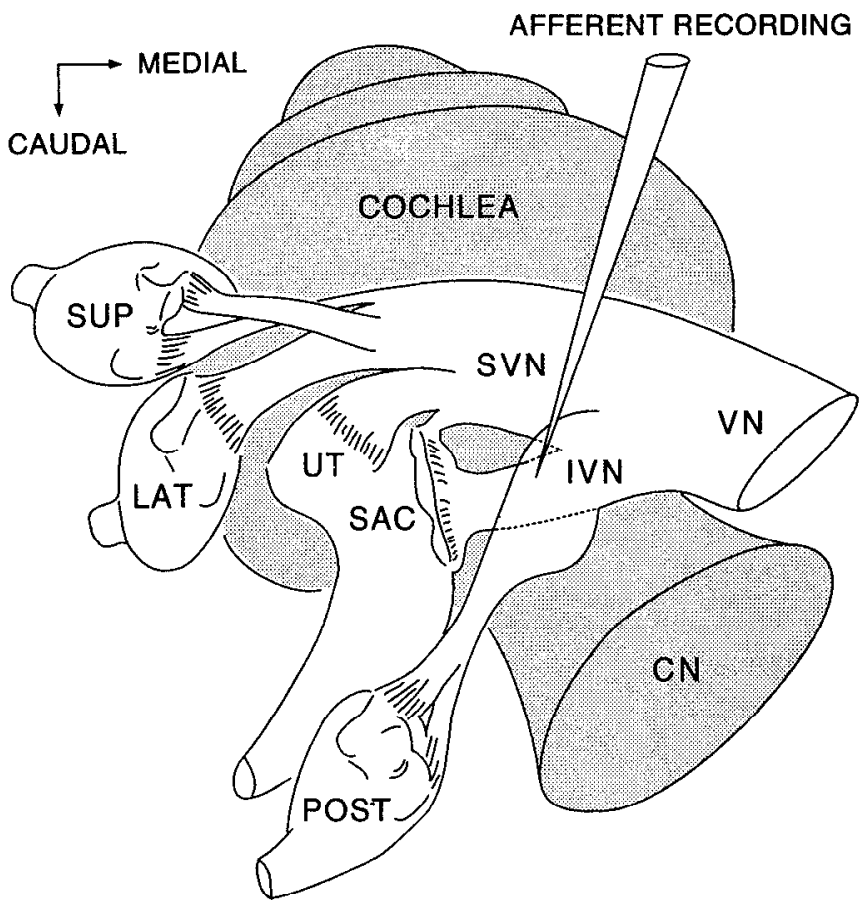

Figure 1. Schematic showing the recording site in relation to the cat's cochlear and vestibular systems. The shaded areas represent the cochlea and cochlear nerve $(C N)$. The unshaded areas represent the vestibular apparatus, which consists of two otolith organs ( $S A C$, saccule; $U T$, utricle) and three semicircular canals (SUP, superior; $L A T$, lateral; $P O S T$, posterior). The vestibular nerve $(V N)$ innervates the vestibular organs through its superior division $(S V N)$ and inferior division $(I V N)$. Acoustically responsive vestibular neurons were recorded in the inferior division, which innervates the saccule and the posterior semicircular canal.

background spike activity. Condensation clicks were then delivered at a rate of $10 \mathrm{clicks} / \mathrm{sec}(n=500)$ at the maximal amplitude of the acoustic system. These were followed by an identical sequence of rarefaction clicks. Tone bursts $(800 \mathrm{~Hz}, 50 \mathrm{msec}$ duration) were then delivered at a rate of three bursts/sec $(n=64)$ with an amplitude of $80 \mathrm{~dB}$ SPL. The tone-burst amplitude was then incremented by 5 or $10 \mathrm{~dB}$ and the tone burst sequence repeated until the sound level reached $110 \mathrm{~dB}$ SPL. Collection of a complete data set (all sound levels tested) required 710 min.

Injury discharges. Not infrequently, units displayed abnormal discharges (e.g., sudden increases in background activity) consistent with neural injury. This phenomenon has been previously associated with proximity of the recording electrode to the cell body (Walsh et al., 1972). Injury discharges sometimes stopped spontaneously or after slight retraction of the electrode, thus allowing the unit to be studied further. In other cases, injury discharges led to wide, multiphasic waveforms or erratic bursts of spikes, followed by loss of neural activity.

Occasionally, we obtained click responses during periods of minor injury discharge because we continued to find robust short-latency responses in the presence of elevated background activity. No measurements were made of tone-burst responses during injury discharge.

Intracellular labeling. In eight experiments, one or more fibers with intracellular DC potentials more negative than $-30 \mathrm{mV}$ were injected intracellularly with a buffered solution of $2 \%$ biocytin (containing 0.05 м Tris, $0.45 \mathrm{M} \mathrm{KCl}$ ) with methods as described for horseradish peroxidase (Liberman and Oliver, 1984). Injection current waveforms were square waves ( $100 \mathrm{msec}$ period, $50 \%$ duty cycle) with an amplitude of 2-7 nA for periods ranging from 1 to $8 \mathrm{~min}$. After a minimum $24 \mathrm{hr}$ survival time, cats were perfused vascularly with $4 \%$ paraformaldehyde, and the brain was removed en bloc with attached cranial nerves VII and VIII. In one case, the saccule was separately microdissected from the bony labyrinth. All tissue was embedded in gelatin-albumin and 80 $\mu \mathrm{m}$ vibratome sections were cut in the horizontal plane. Tissue sections were incubated overnight in avidin-horseradish peroxidase complex 
- regular

- IRREGULAR, RESPONSIVE

- IRREGULAR, UNRESPONSIVE

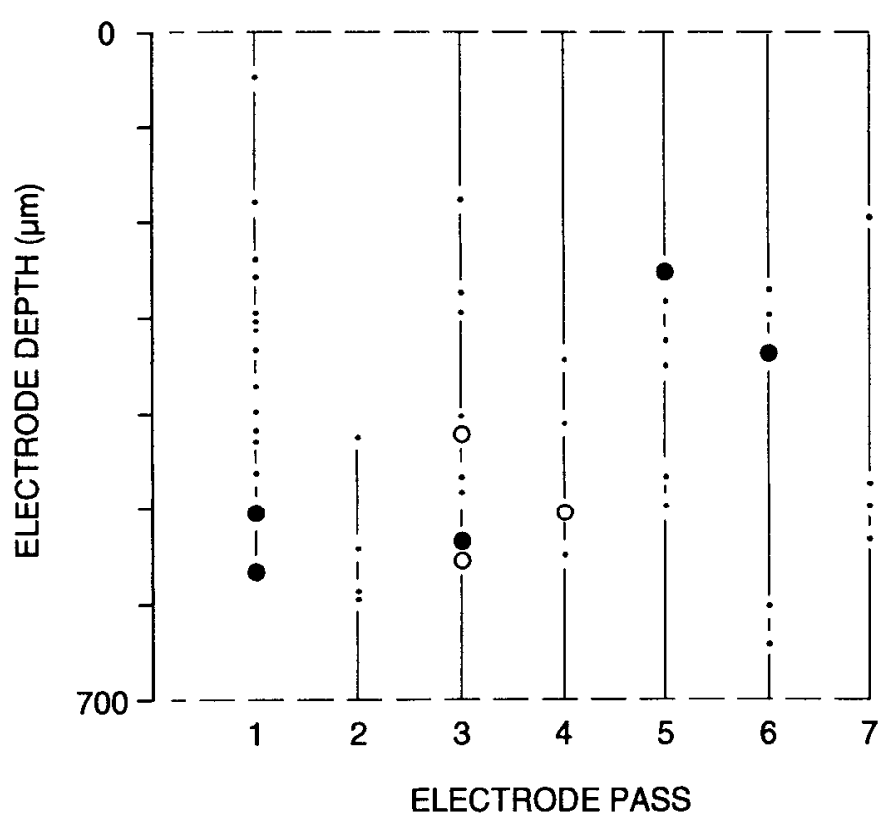

Figure 2. Occurrences of acoustically responsive units encountered on one electrode puncture of the inferior vestibular nerve. Each column represents a separate pass (same location) in which the electrode was advanced slowly and each unit encountered was noted. Vertical lines indicate the extent of each pass (the electrode was only partially backed up between passes 1 and 2). Each encountered unit was classified according to the regularity of its spontaneous activity as judged by listening to amplified discharges played through a speaker. All units that displayed audible irregularity were tested for acoustic responsiveness. Of the eight irregularly discharging units encountered at this site, five showed an increased discharge rate in response to an $800 \mathrm{~Hz}$ tone burst at $115 \mathrm{~dB}$ SPL.

(Horikawa and Armstrong, 1988) and then reacted with diaminobenzidine.

Analysis. Mean spike rates were calculated from poststimulus time (PST) histograms over the $50 \mathrm{msec}$ duration of the tone-burst stimulus (e.g., Fig. 6A). To quantify the tendency of a unit to synchronize to individual parts of a tone cycle, we first computed a postzero crossing (PZC) histogram relating spike occurrences to the positive-going zero crossings of earphone voltage (e.g., Fig. 6C). A fast Fourier transform was computed from the PZC histogram, and from this we obtained the synchronization index and the response phase. The synchronization index was defined as the magnitude of the first (fundamental) Fourier component divided by the total number of spikes in the PZC histogram, and the response phase is the phase of the first Fourier component (Goldberg and Brown, 1969; Johnson, 1980; Gifford and Guinan, 1983). The synchronization index ranges from 0 (no synchronization) to 1 (all spikes in one bin).

\section{Results}

\section{Unit location, definition, and prevalence}

Location. An electrode probing in and near the inferior vestibular nerve encounters several types of fibers that must be distinguished. The recording site is in the caudal portion of Scarpa's ganglion, which contains the cell bodies of primary vestibular afferents that innervate the saccule and posterior semicircular canal (Fig. 1). Also passing through this region are cochlear efferent fibers that exit in the nearby vestibulocochlear anastomosis (bundle of Oort). The site also directly overlies the cochlear nerve. Typically, vestibular nerve fibers and cell bodies were found to be intermingled with cochlear efferent fibers in the superficial $0.5-1.0 \mathrm{~mm}$ of each electrode penetration. Units that had regular spontaneous activity and long-latency ( $\geq 5 \mathrm{msec}$ ) responses to ipsilateral or contralateral sound were considered to bc cochlear cfferents (Liberman and Brown, 1986). Decper electrode penetrations usually entered the cochlear nerve and resulted in an abrupt transition to cochlear nerve units with characteristic Poisson-like spontaneous activity and low-threshold acoustic responses (Kiang et al., 1965). All remaining fibers were presumed to be vestibular afferents or efferents. Units reported here were identified as afferents by their extremely shortlatency responses to sound.

Definitions. We define a vestibular unit to be acoustically responsive if its discharge rate increased in response to $800 \mathrm{~Hz}$ tone bursts at $\leq 115 \mathrm{~dB}$ SPL. Using this criterion, we have recorded 229 acoustically responsive units in the inferior vestibular nerves of 21 cats. Some of these observations were made in experiments focused on other issues, so that the total number of units does not adequately reflect their prevalence and the ease with which the units were found. We present here data from 57 units recorded in three cars of three cats.

With spike discharges monitored using a loud speaker, two classes of vestibular afferent units were distinguished based on the regularity of their spontaneous discharges. As demonstrated by Walsh et al. (1972), audible determination of unit regularity correlates well with statistical measures such as coefficient of variation (CV) and skew. In the present work, statistical analysis of spike regularity was done only for vestibular afferents that responded to sound. The statistics from these fibers correspond well with those of irregular vestibular afferents as described by Walsh et al. (1972). In particular, the acoustically responsive vestibular afferents described here had $\mathrm{CV} \geq 0.15$ (see Walsh et al., 1972, for definitions) and skew $\geq 0.9$ (McCue, 1993).

Prevalence. Figure 2 shows a record of all vestibular units recorded in one electrode puncture in which the electrode was advanced and partially retracted seven times. Units with regular discharges predominated at the recording site $(n=40)$, but none of these were found to be acoustically responsive. Of the eight irregular units recorded, five were "acoustically responsive," that is, responded with a rate change at sound levels below 115 $\mathrm{dB}$ SPL. Because the hallmarks of these units were acoustic responsiveness and irregular discharge, we refer to them as $A R I D$ units. The prevalence of ARID units was site dependent; in some penetrations, $100 \%$ of the irregular units were acoustically responsive. The prevalence represented in Figure 2 is, however, fairly typical for our later experiments.

\section{Responses to clicks}

Not all ARID units responded to acoustic clicks at the sound levels used here. Most (44 of 57) did, however, and these typically responded with minimum latencies of $0.7 \mathrm{msec}$, which contrasts with the minimum latencies of $1.0 \mathrm{msec}$ observed in cochlear afferents (Kiang et al., 1965; Ruggero and Rich, 1987).

ARID units that responded to clicks fell into one of two classes based on their responses to condensation and rarefaction clicks (Fig. 3). ARID units in which the shortest-latency response was obtained with condensation clicks were called "PUSH" units (Fig. 3A,B). In contrast, "PULL" units had their shortest-latency response for rarefaction clicks (Fig. $3 C, D$ ). The shortest-latency $(<1.0 \mathrm{msec})$ click responses were almost always followed by a period of reduced firing and then another period $(>1.5 \mathrm{msec})$ 


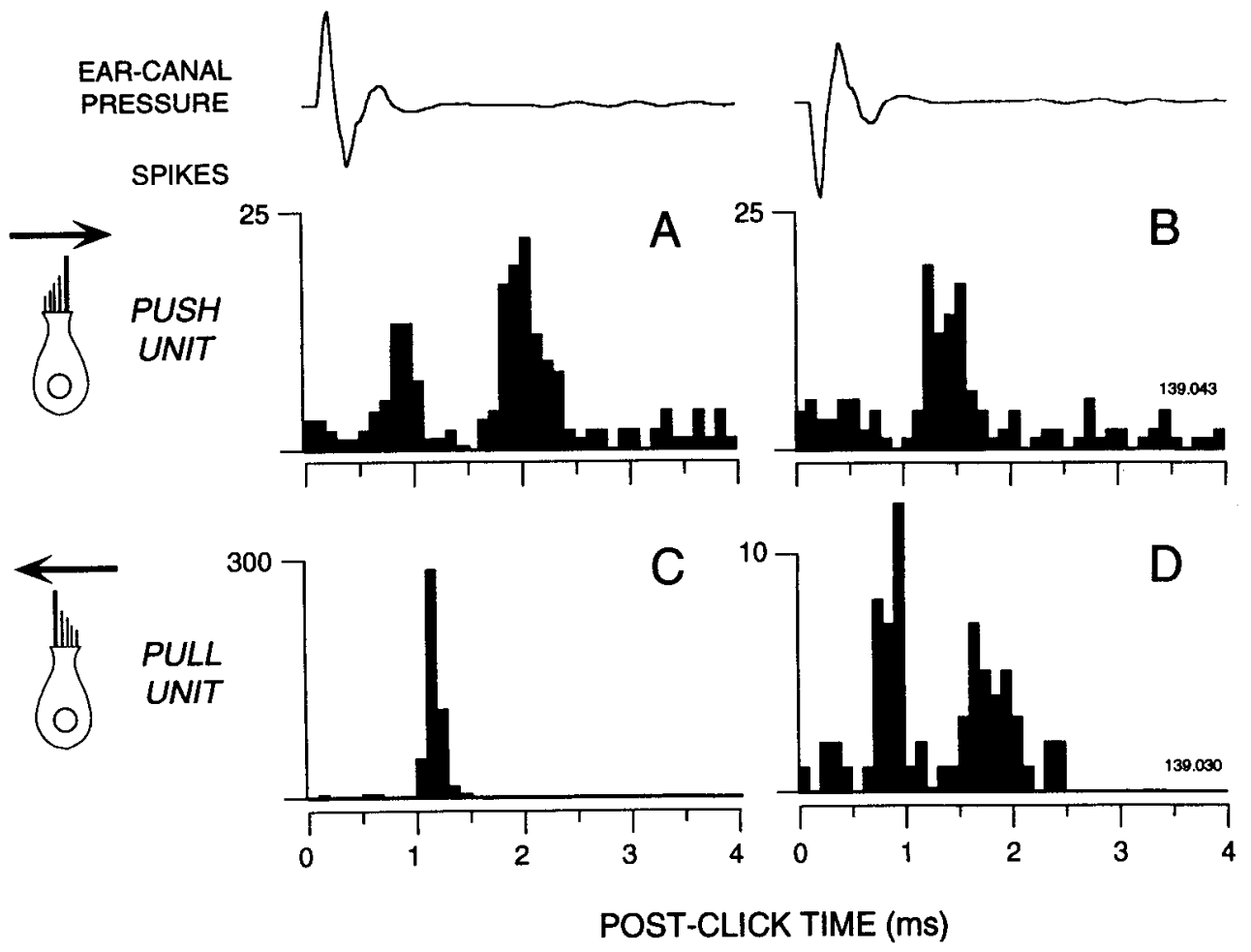

Figure 3. Separation of acoustically responsive vestibular units into two classes (PUSH and PULL) based on responses to condensation and rarefaction clicks. The traces show the pressure waveforms recorded from the microphone near the tympanic membrane. $A--D$ are PST histograms constructed from the spikes of two different units that are representative of their respective classes. PUSH units $(A, B)$ responded with shortest latency to condensation clicks $(A)$, while PULL units $(C, D)$ responded with shortest latency to rarefaction clicks $(D)$. There were only very small differences in the magnitude spectra of the condensation and rarefaction clicks, and these differences cannot account for the latency differences in $A-D$. Drawings at left indicate a hypothetical hair cell orientation, and arrows indicate the excitatory (depolarizing) direction. The bin width is 0.1 msec. The total number of spikes that occurred in each bin is plotted for 500 repetitions of the click. The hest frequencies for the two units were $571 \mathrm{~Hz}$ $(A, B)$ and $718 \mathrm{~Hz}(C, D)$.

of incrcased firing (Fig. $3 A, D$ ). In some cases, the second period of increased firing exceeded the first in amplitude (Fig. $3 A$ ).

Inversion of the click shifted the peaks of the click response in a predictable fashion such that a PUSH unit's response to a condensation click (Fig. $3 A$ ) was similar to a PULL unit's response to a rarefaction click (Fig. $3 D$ ). These mirrored responses are consistent with a simple hypothesis: $P U S H$ and PULL units are activated by movement of hair-cell stereocilia and arise from hair cells that are morphologically polarized(Wersäll et al., 1965) in opposite directions.

\section{Responses to tone bursts}

Frequency. Although responses were obtained at frequencies as low as $100 \mathrm{~Hz}$ and as high as $2.5 \mathrm{kHz}$, ARID units responded best to frequencies between 500 and $1000 \mathrm{~Hz}$ (McCue, 1993). For simplicity, we chose to study the units at one frequency $(800 \mathrm{~Hz})$, which was near the best frequency for all units.

Firing rate. Figure 4 shows one ARID unit's response to 800 $\mathrm{Hz}$ tone bursts as the sound level was increased in $5 \mathrm{~dB}$ steps from $80 \mathrm{~dB}$ SPL to $110 \mathrm{~dB}$ SPL. With few exceptions, ARID units exhibited no increases in discharge rate below $90 \mathrm{~dB}$ SPL (e.g., Fig. 4). As the sound level was increased above $90 \mathrm{~dB}$ SPL, discharge rates increased monotonically. No firing-rate plateau was observed at the highest sound levels in any unit examined. For the aggregate population of ARID units, firing rate increased from a mean background of 22 spikes/sec at $80 \mathrm{~dB} \mathrm{SPL}$ to a mean of 127 spikes/sec at $110 \mathrm{~dB}$ SPL (Fig. 5). The maximum sound-evoked firing rate observed in any unit was 340 spikes/ $\sec$ (at $110 \mathrm{~dB}$ SPL).

Synchronization. While the mean firing rate threshold was between 90 and $100 \mathrm{~dB}$ SPL (Fig. 5), the spikes tended to synchronize to a preferred phase of the tone cycle ("phase lock") at levels approximately $10 \mathrm{~dB}$ lower (Fig. 6). For example, the unit in Figure 6 showed a clear rate increase at 95 dB SPL (Fig. $6 \mathrm{~A}$ ), and phase locked clearly at $85 \mathrm{~dB}$ SPL (Fig. $6 \mathrm{C}$ ).

Relationships between rate and phase-locking are shown for

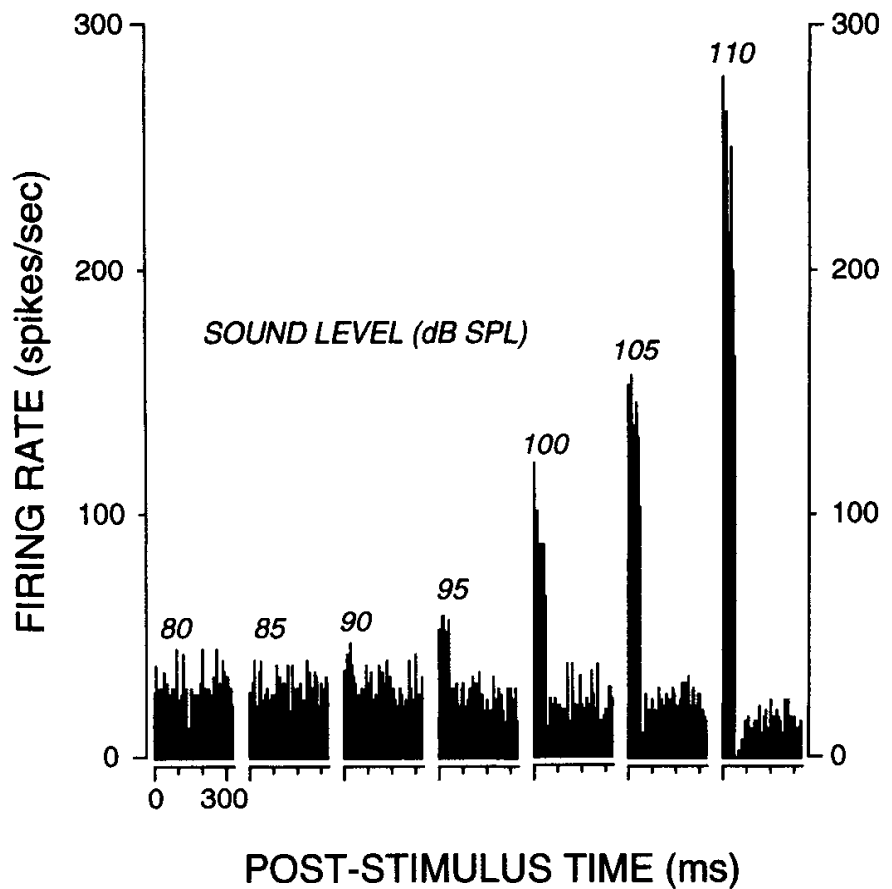

Figure 4. PST histograms from an acoustically responsive vestibular unit for $800 \mathrm{~Hz}$ tone bursts of increasing amplitude. Each PST histogram represents responses to 64 tone bursts of $50 \mathrm{msec}$ duration delivered at a rate of $3 / \mathrm{sec}$. Tone burst onset is at $t=0$. Bin width is $6.7 \mathrm{msec}$. 


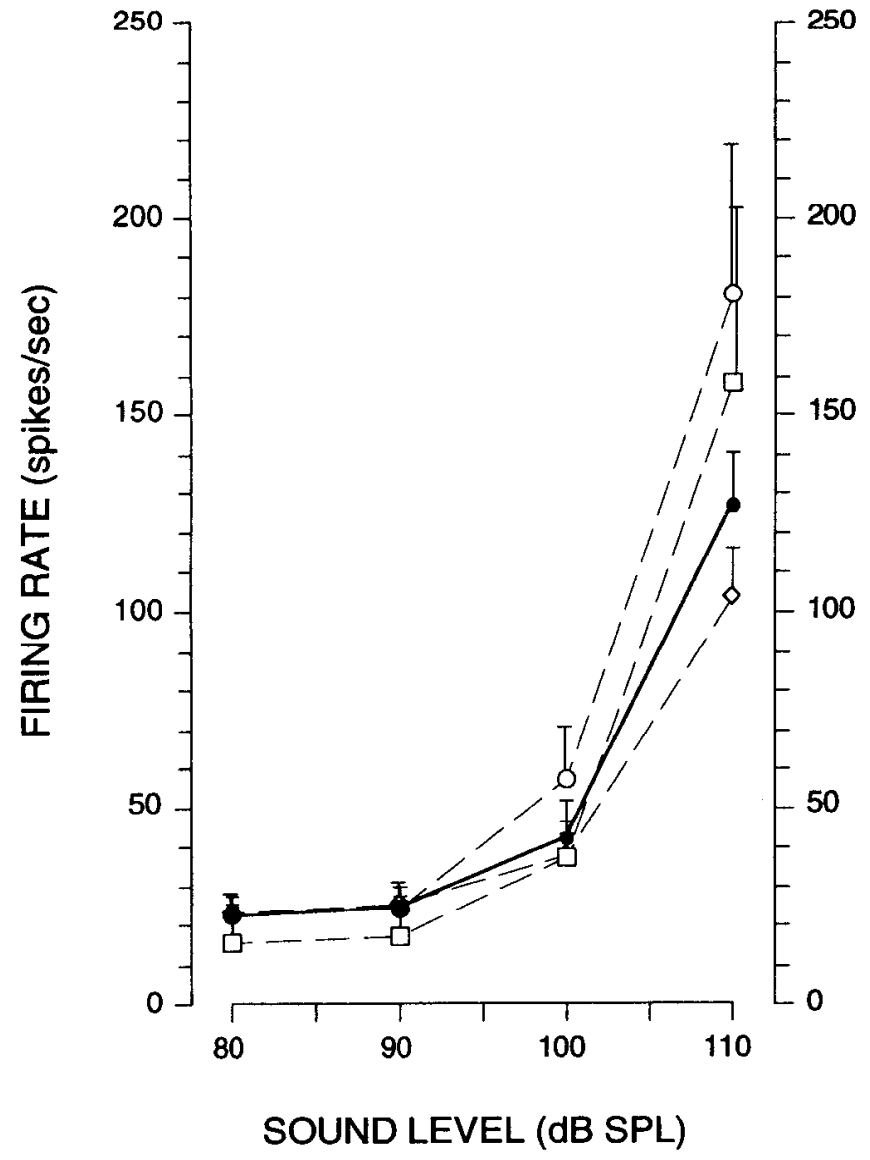

Figure 5. Mean firing rates in acoustically responsive vestibular units at four sound levels. Units in which PST histograms were obtained at each level were included. The solid line represents the mean + SEM for all such units $(n=38)$. Each dashed line represents mean + SEM for units from one ear (circles, $n=8$; squares, $n=5$; diamonds, $n=25$ ). Mean firing rate was calculated for each unit over the $50 \mathrm{msec}$ stimulus interval of PST histograms similar to those shown in Figure 4.

four units in Figure 7. Monotonic increases in synchronization were observed beginning at levels at or near $80 \mathrm{~dB}$ SPL. The average synchronization index for ARID units was quite high (0.77 at $110 \mathrm{~dB}$ SPL; Fig. 8).

Figure 9 shows synchronization and rate plotted as a function of sound level for 25 ARID units. A dichotomy occurs in the synchronization indices at 90 and $100 \mathrm{~dB}$ SPL (Fig. 9A). Units with the lower synchronization at these sound levels (Fig. 9A, dashed lines) had higher rate thresholds and lower maximal rates (Fig. 9B, dashed lines). This phenomenon (bimodal synchronization) bears no clear relationship to the PUSH-PULL dichotomy.

Phase. As sound level increased, ARID units began to respond at a preferred phase of the stimulus cycle (Fig. $6 \mathrm{C}$ ). Figure 10 shows polar plots of synchronization index (radial coordinate) versus response phase (angular coordinate) for all units that achieved a synchronization index $>0.3$ (this criterion was chosen because response phase becomes more reliable with increased synchronization and firing rate). At 90-100 dB SPL, phases clustered into two classes lying approximately $180^{\circ}$ apart (Fig. 10). Almost all units showed a phase advance of about $30^{\circ}$ as the sound level increased from 90 to $110 \mathrm{~dB}$ SPL (e.g., Fig. 6). At $110 \mathrm{~dB}$ SPL, ARID units that achieved the highest levels of synchronization (i.e., index $>0.75$ ) fell into two classes $180^{\circ}$ out of phase, but a few units with lower (though still marked) synchronization did not. These units tended to fire $90^{\circ}$ out of phase from the majority of units (Fig. 10, top).

\section{Relationship of click and tone burst responses}

A strong relationship was found between the preferrcd phascs of units and the latencies of their click responses (Fig. 11). With few exceptions, units that responded with shorter latency to condensation clicks (PUSH units) had a phase near $90^{\circ}$, while those units that responded with shorter latency to rarefaction clicks (PULL units) had a phase near $270^{\circ}$ (Fig. 11).

\section{Mechanism of acoustic conduction}

We wondered whether acoustic activation of these vestibular afferents was accomplished by ossicular transmission (i.e., through the middle ear) or through some nonossicular mechanism (e.g., bone conduction). A serendipitous observation in one experiment provided strong evidence for ossicular transmission. The acoustic middle-ear muscle reflexes in the cats were normally suppressed by the anesthesia used in these experiments (Borg and Møller, 1975), so we sometimes left the muscles intact. In one cat, large doses of anesthcsia wcrc rcquired to suppress the reflex long after the usual indicators (heart rate, respiration, withdrawal reflex) indicated deep anesthesia. We were alerted to the presence of the reflex by obtaining uncharacteristic responses while recording from ARID units (Fig. $12 B$ ). The three ARID units recorded before inactivation of the reflex discharged normally at the onset of the $50 \mathrm{msec}$ tone burst but then abruptly stopped firing $15 \mathrm{msec}$ after the onset. The attenuation of cochlear response at that time indicated a greater than $20 \mathrm{~dB}$ reduction of ossicular transmission by the middle ear muscles (in Fig. $12 B$, the response at $110 \mathrm{~dB}$ was reduced to less than that at $90 \mathrm{~dB}$ ). This reduction of the response at $800 \mathrm{~Hz}$ is too large and occurs too fast to be accounted for by medial olivocochlear efferents (Gifford and Guinan, 1987; Guinan and Gifford, 1988). After complete inactivation of the acoustic reflex by anesthesia, the cochlear response no longer showed attenuation of ossicular transmission (Fig. 12A). Fourteen ARID units were recorded subsequently and found to discharge continuously throughout the tone burst. We conclude that the acoustic input to ARID units enters the labyrinth principally via normal middle-ear transmission.

\section{Anatomical identification}

Seven ARID cell bodies were labeled by intracellular injection of biocytin and all were found to be bipolar ganglion cells located in the inferior division of Scarpa's ganglion near the exit of the saccular nerve. Complete labeling of central and peripheral projections was difficult to obtain. However, in one ear, three ARID units were injected and two labeled cells were recovered. The peripheral processes of both cells extended to the sensory epithelium of the saccule. The central process of one cell was reconstructed and found to project to the vestibular nuclei (Fig. $13 D-F)$. A labeled arborization was also found on cell bodies in a poorly defined region near the ventromedial edge of the cochlear nucleus (Fig. 13C). No terminals were observed within the cochlear nucleus.

\section{Discussion}

Whether the mammalian vestibular system retains some role in hearing is the subject of a long debate ignited by the discovery of acoustic responsiveness in the saccule of lower vertebrates, 


\section{A PSt histogram B PSt histogram - expanded C PZC histogram}

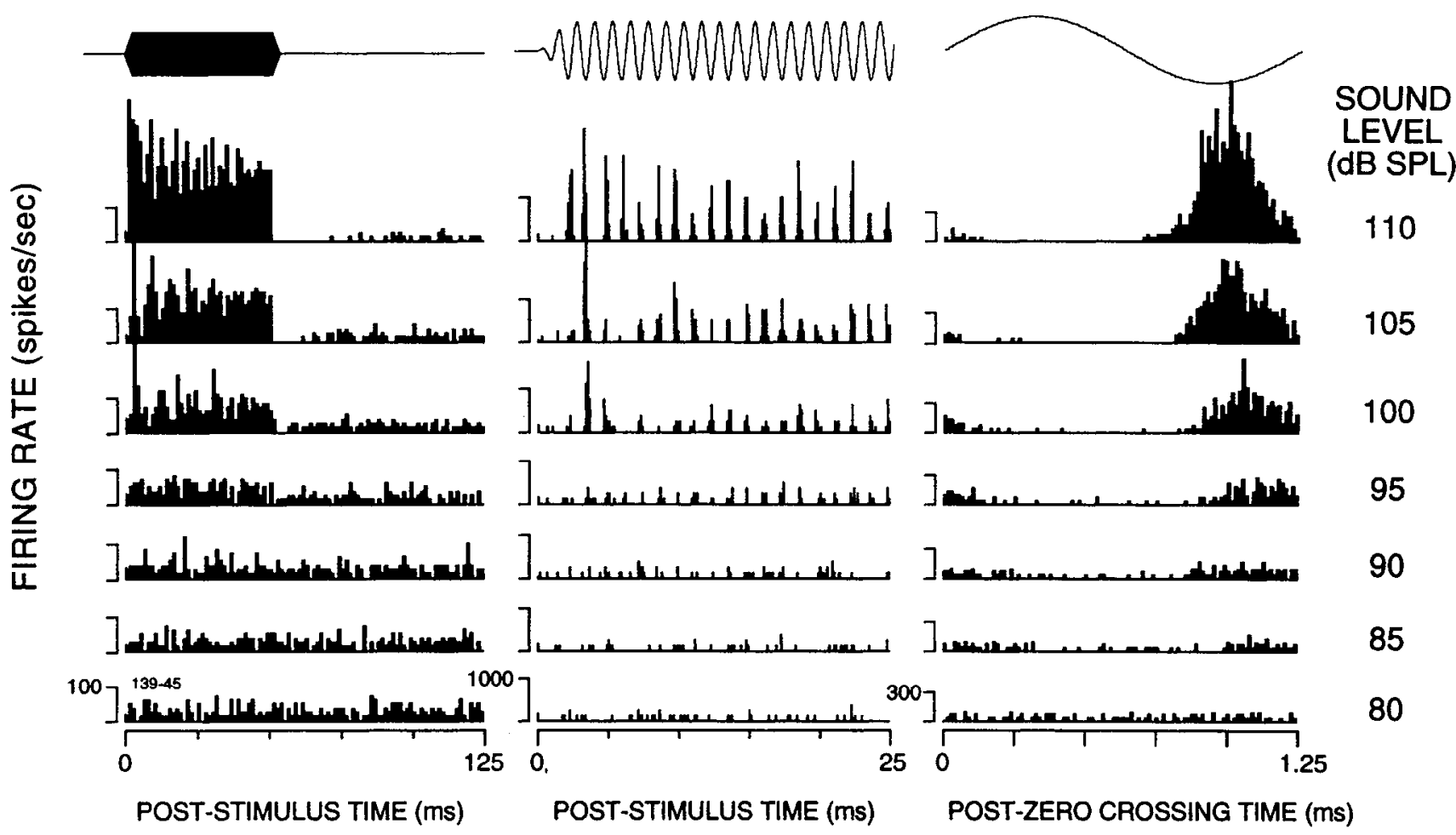

Figure 6. Relationship of phase locking and rate for an acoustically responsive vestibular unit. Top traces depict voltage waveforms at the earphone. $A$. PST histograms showing firing rate increases occurring at $\leq 95 \mathrm{~dB}$ SPL. $B$. Expanded PST histograms showing the tendency for discharges to occur at a preferred phase of the stimulus cycle. $C$, Postzero crossing histograms showing tone synchronization occurring at levels $\leq 85 \mathrm{~dB}$ SPL. Note that the preferred phase in $C$ advances (moves to the left) noticeably with increasing sound level. The stimulus was an $800 \mathrm{~Hz}$ tone burst with a $50 \mathrm{msec}$ duration and $2.5 \mathrm{msec}$ rise time. Same unit as shown in Figure 4.

notably rays, fish, and amphibians (Lowenstein and Roberts, 1951; Popper and Fay, 1973; Moffat and Capranica, 1976). The debate was fueled by ablation experiments that showed little or no deficit in equilibrium after destruction of the saccule in monkeys (Igarishi and Kato, 1975).

For the vestibular system in mammals to have a useful role in hearing, it must respond naturally to sounds at levels which are nontraumatic, and the signals it transmits centrally must be processed as auditory information, that is, be interpreted as sensation or used to trigger behaviors. A variety of evidence suggests that saccular afferents play a role in mammalian responsivity to sound.

\section{Saccular acoustic responses in the cat}

The available anatomical evidence suggests that the ARID afferents reported here are of saccular origin. Grossly, the recording site is distal to the vestibular bifurcation and the only afferents likely to be present are those supplying the saccule and posterior semicircular canal (Fig. 1). Our anatomical experiments have demonstrated projections to the saccule from two well-labeled ganglion cells (e.g., Fig. 13). All five of the remaining labeled ganglion cells had labeled fibers that extended varying distances toward the saccular nerve. Finally, there was no evidence of labeling in the posterior canal nerve.

Our physiological evidence is also consistent with the interpretation that ARID afferents are of saccular origin. The PUSHPULL dichotomy among ARID afferents in their responses to clicks (Figs. 3, 11) and tones (Figs. 10,11) suggests that they arisc from hair cells that are morphologically polarized in opposite directions. The hair cells of the saccular macula are morphologically polarized in opposite directions with respect to the striola (Fig. 14), whereas the cristae of the semicircular canals each have hair cells with uniform morphological polarization (Lindeman, 1973).

Irregular discharges have been associated with the large afferent fibers (Goldberg and Fernández, 1977) more prevalent along the central part (striola) of the macula (Lindeman, 1973). The few ARID units we recorded that did not fall into the two polarized (PUSH and PULL) categories (Figs. 10, 11) may have arisen from the curved head of the saccule (Fig. 14A) or from hair cells situated directly in the striola transition zone, in which intermediate morphological polarizations are commonly found (Lindeman, 1973).

The cat saccule is innervated by approximately 1800 primary afferents (Gacek and Rasmussen, 1961), of which the majority have regular background activity (Walsh et al., 1972). According to our criterion for acoustic responsiveness (rate change at levels $\leq 115 \mathrm{~dB}$ SPL), none of the regular afferents from the saccule were acoustically responsive. Some irregularly discharging afferents from the saccule may also be unresponsive, although we cannot rule out the possibility that the insensitive irregular units we encountered (e.g., Fig. 2) arose from the posterior semicircular canal. Because of the unknown mixture of semicircular canal afferents and saccular afferents at the recording site, we are unable to estimate the total number or percentage of irregular saccular afferents that are acoustically responsive. 


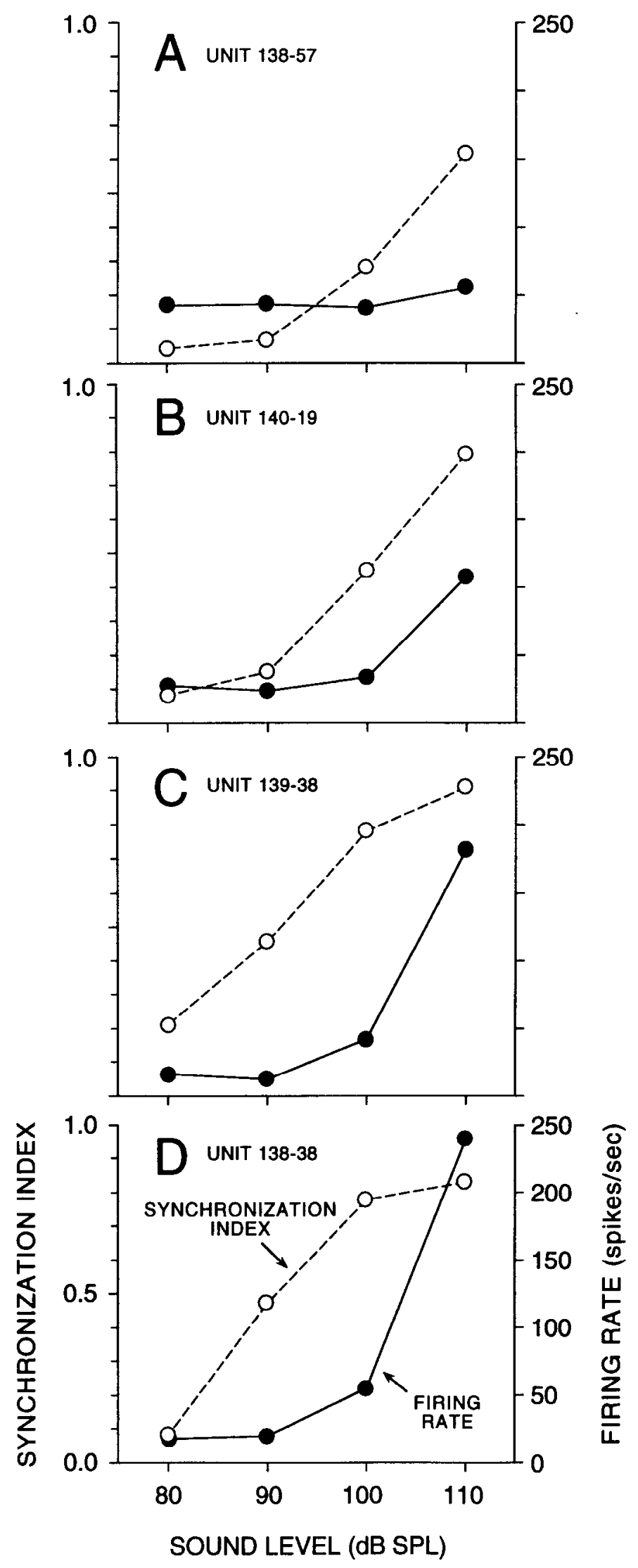

Figure 7. Comparison of firing rate and synchronization in four units at four sound levels. Dashed lines show the synchronization index for each unit (left ordinate). Solid lines show the corresponding firing rate (right ordinate). Units were chosen to illustrate a range of maximal firing rates. In each unit, an increase in synchronization occurred at a level approximately $10 \mathrm{~dB}$ below the level that produced an increase in firing rate. Stimuli were identical to Figure 6.

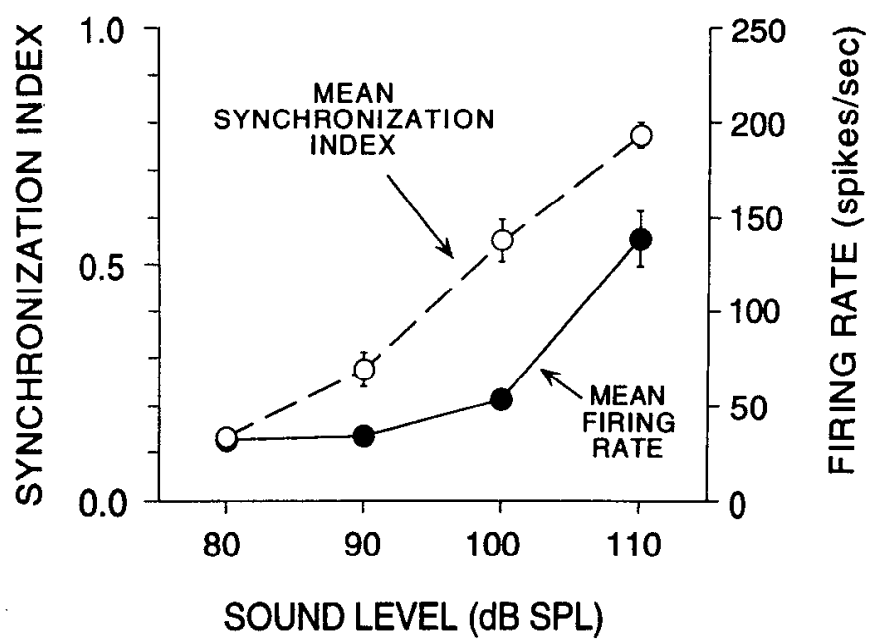

Figure 8. Mean synchronization index and firing rate for all units studied at four sound levels. Units in which complete histograms were obtained at each level were included $(n=38)$. Error bars indicate \pm 1 SEM. Labeling conventions are as for Figure 7.

Acoustic response latency. ARID units routinely respond to acoustic clicks with minimum latencies of $0.7 \mathrm{msec}$ from the onset of voltage to the earphone. This latency is short in comparison to cochlear afferents (minimum latency, $1.0 \mathrm{msec}$; Kiang et al., 1965; Ruggero and Rich, 1987) and may be accounted for in part by shorter acoustical conduction times, a recording sitc closer to the end organ, and larger axon diameters (Gacek and Rasmussen, 1961). Taking the delays associated with these factors into account, the remaining synaptic delay from hair cell to ARID afferent is very short, close to the $0.3-0.4 \mathrm{msec}$ observed in the fastest chemical synapses in the CNS (e.g., see Guinan and $\mathrm{Li}, 1990$ ). The short latency of ARID afferents might also be consistent with an electrical synapse between the vestibular hair cells and the calyx afferents, as suggested by Spoendlin (1966). In either case, ARID vestibular afferents represent the fastest known pathway for the conduction of acoustic information into the CNS, and this property may turn out to be an important clue to their function as well as a useful feature in identifying their postsynaptic projections.

Acoustic response threshold. ARID units respond briskly within the upper range of normal hearing. The sound level at which they might make functional contributions to hearing depends, however, on the cues recognized by the CNS. If rate changes are necessary for the detection of the responses, then ARID units have minimum thresholds near $90 \mathrm{~dB}$ SPL (Figs. 7, 8). If phase locking is detectable without an increase in mean firing rate, then acoustic thresholds are closer to $80 \mathrm{~dB}$ SPL (Figs. 7, 8).

Acoustic stimulation mechanisms. The marked suppression of ARID unit responses during contractions of the middle-ear muscles (Fig. 12) argues strongly for an ossicular conduction pathway. The possibility that ARID units play some role in hearing is clearly strengthened by evidence that these units are activated through normal middle-ear sound transmission.

The abrupt cut off of ARID unit responses by middle-ear muscle (MEM) contractions (Fig. 12) might suggest that in unanesthetized cats, the role of ARID units is restricted to providing only an onset response. However, the abrupt cutoff must bc duc to an MEM responsc consisting of an initial overshoot followed by a damped oscillation (e.g., Guinan and McCue, 1987). MEM contractions regulate the sound drive to the cochlea but never perfectly; as the external sound level is increased, the sound reaching the cochlea always increases. In the steady 

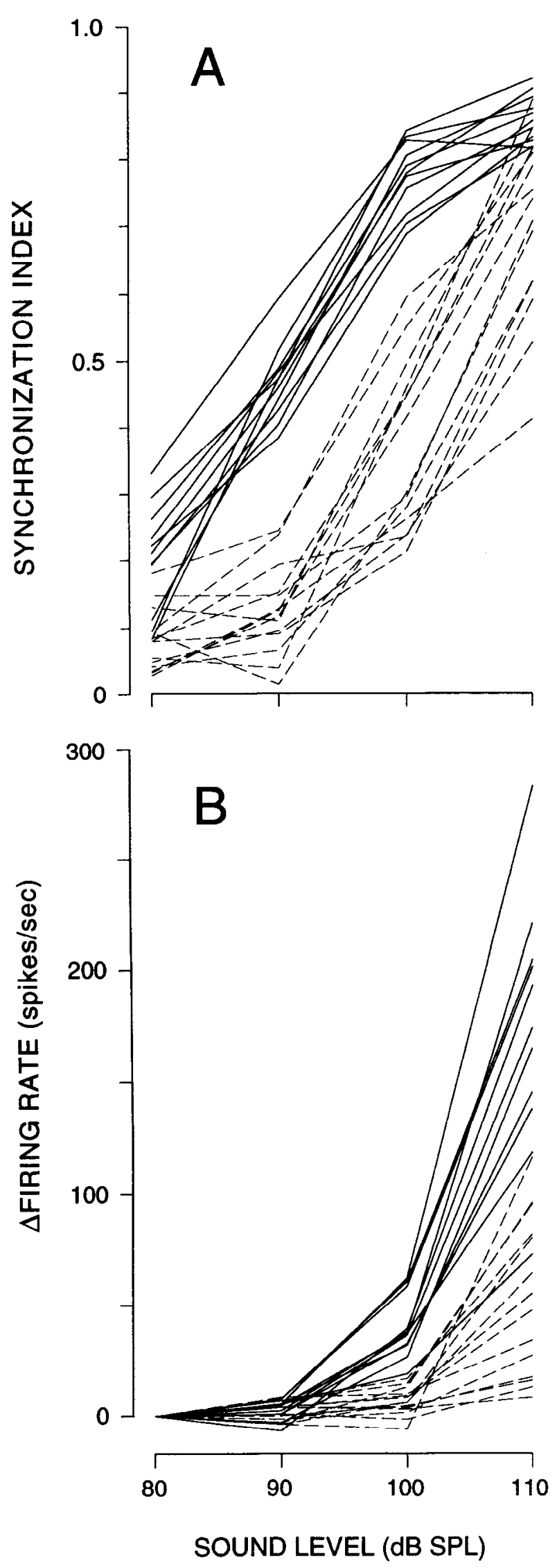

Figure 9. Synchronization and firing rate changes for 25 units at four sound levels. $A$, Synchronization indices. $B$, Evoked firing rate increase (change from the background rate at $80 \mathrm{~dB}$ SPL) for the same units state, the attenuation produced by MEM contractions results in the increase in cochlear sound being only a fraction of the increase in external sound.

The interpretation that ARID vestibular afferents are excited acoustically and not by vibration is supported by a control experiment in which two different sound sources were put in one ear (McCue, 1993). One source was the normal condenser earphone that pressed rigidly against the bone of the tympanic ring. The other source was a dynamic earphone (Bayer DT48) that sat on a foam pad and was loosely coupled to the ear with flexible plastic tubing. For both sources, the acoustic output near the tympanic membrane was calibrated with the probe tube and condenser microphone (see Materials and Methods). For the ARID vestibular afferents obtaincd in this experiment, virtually identical thresholds (in sound pressure level at the tympanic membrane) as a function of frequency were obtained with the two earphone systems, even though the loosely coupled system would be expected to produce much less vibration of the head.

The mechanisms by which sound excites irregular, but not regular, saccular afferents are interesting to consider. We presume that stapes motion causes movement of inner ear fluids, which in turn moves the saccular macula and bends its hair cell stereocilia. It seems likely that the position of the saccule directly opposite the stapes in the vestibule is an important factor in this fluid pathway. The order of magnitude, or greater, difference in acoustic sensitivity between regular and irregular saccular afferents seems unlikely to be due to spatial differences in the acoustic response of the macula or differences in the bending of hair cell stereocilia. More likely, this difference in acoustic sensitivity is due to differences in the dynamics of the responses at the hair cell and/or afferent fiber level.

Two aspects of the surgical procedure bear on the question of whether ARID responses occur in behaving animals. These include the opening of the posterior fossa of the cranium and the drilling of the superficial temporal bone. It is conceivable that opening the posterior fossa alters the acoustic mechanics of the vestibular system, since the vestibular system is contiguous with the intracranial space through several pathways (principally via the cochlear aqueduct; Beentjes, 1972). Since the cochlear aqueduct attenuates pressure variations at frequencies as low as those of breathing (Beentjes, 1972), and its long, thin structure indicates that it acts as a lowpass filter, the cochlear aqueduct must attenuate acoustic transmission by several orders of magnitude in the frequency range at which ARID units are sensitive $(800 \mathrm{~Hz})$. This suggests that opening the posterior fossa would produce little change in acoustic flow within the labyrinth.

The drilling of the temporal bone is of more concern, because fenestration of the labyrinth can produce dramatically lowered acoustic thresholds in the vestibular afferents of many animals (Tullio, 1938; Mikaelian, 1964; Wit et al., 1984; Ribaric et al., 1992). For this reason, we meticulously maintained the integrity of the bony labyrinth. In one instance, reported elsewhere (McCue, 1993), we attempted to record from acoustically responsive vestibular afferents near their brainstem entry zone and were able to do so without drilling the temporal bone. Although we had more difficulty finding acoustically responsive

shown in $A$. To improve the accuracy of the synchronization index calculation, only units that had background firing rates $\geq 10 \mathrm{spikes} / \mathrm{sec}$ are plotted. Dashed lines indicate units that have synchronization indices $<0.3$ at $90 \mathrm{~dB}$ SPL and $<0.65$ at $100 \mathrm{~dB}$ SPL. 

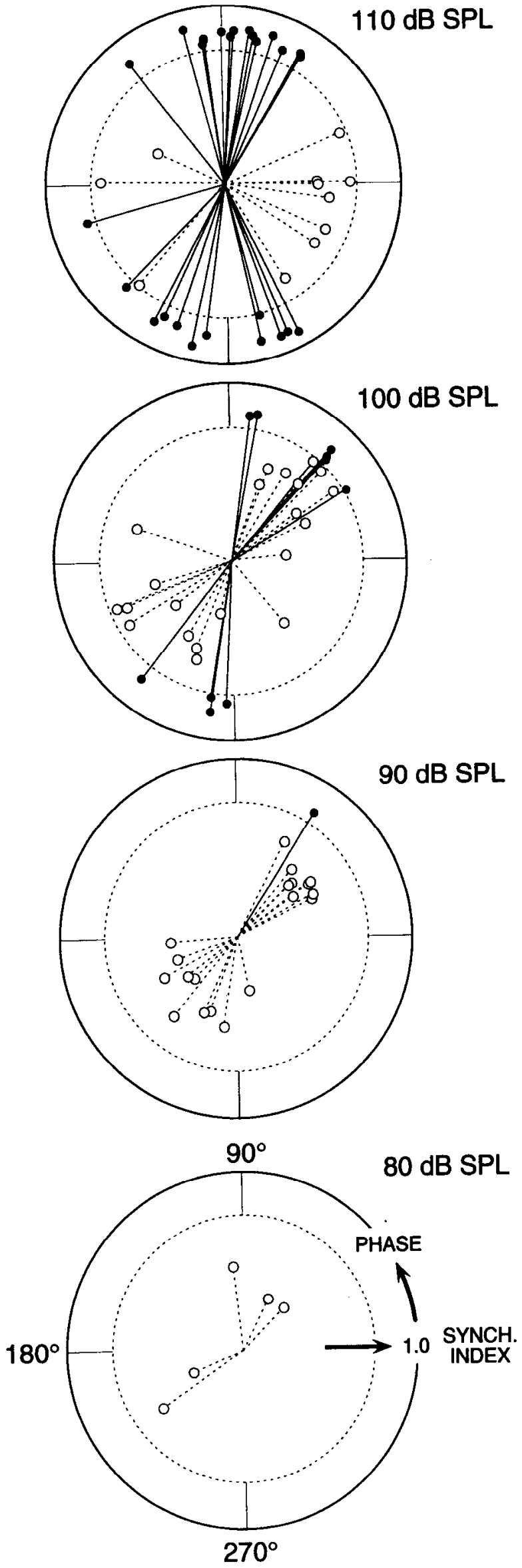

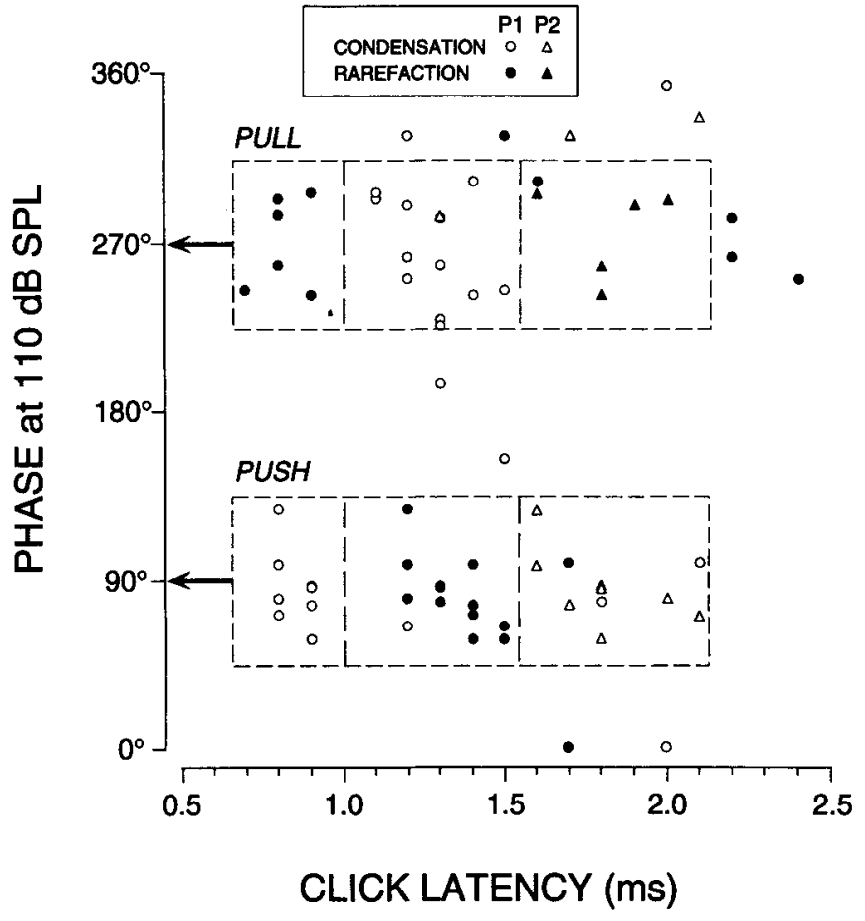

Figure 11. Relationship between click latency and preferred phase for tonal stimulation. Each symbol indicates the latency of a peak in a click PST histogram (see Fig. 3) accumulated in response to condensation (open symbols) or rarefaction (solid symbols) clicks. Initial peaks $(P 1)$ are represented by circles, any secondary peaks $(P 2)$ are represented by triangles. The upper and lower dashed boxes are regions of identical size, centered on $270^{\circ}$ and $90^{\circ}$, respectively, chosen to show that each corresponding subregion contains an almost homogeneous population of points. PULL units (top boxes) responded with shortest latency to rarefaction clicks and had preferred phases which clustered around $270^{\circ}$. PUSH units (bottom boxes) responded with shortest latency to condensation clicks and had preferred phases which clustered around $90^{\circ}$. Response phases were calculated from PZC histograms (see Fig. $6 \mathrm{C}$ and Materials and Methods). Latency information was taken from all PST maxima that exceeded by $100 \%$ the average background activity during the $80 \mathrm{msec}$ intraclick interval. Occasionally, this criterion was met by the second peak when the first peak had not met the criterion (triangle with no corresponding (ircle). Units that responded to tone bursts but not to clicks are not included.

afferents at this more proximal site, we attribute this difficulty to the presence of numerous afferents from unresponsive end organs.

Saccular acoustic responses in species other than the cat

The extrapolation of our results to awake and behaving mammals is supported by consistent findings in other mammalian preparations in which less extensive surgery was undertaken (Townsend and Cody, 1971; Young et al., 1977; Cazals et al.,

Figure 10. Polarization of acoustically responsive vestibular units into at least two classes based on response phases to tonal stimuli. Each panel shows a polar plot of response phase versus synchronization index (S.I.) for all units at one sound level. Representation scheme: S.I. $>0.75$ (solid lines and solid circles), $0.75>$ S.I. $>0.30$ (dashed lines and open circles), S.I. $<0.3$ (points omitted because of phase inaccuracy). Outer circle, $\mathrm{SI}=1.0$ (perfect synchronization); inner circle, S.I. $=0.75$ (high synchronization); center, SI $=0$ (no synchronization). Response phase and synchronization were calculated from PZC histograms (see Fig. $6 \mathrm{C}$ and Materials and Methods). 


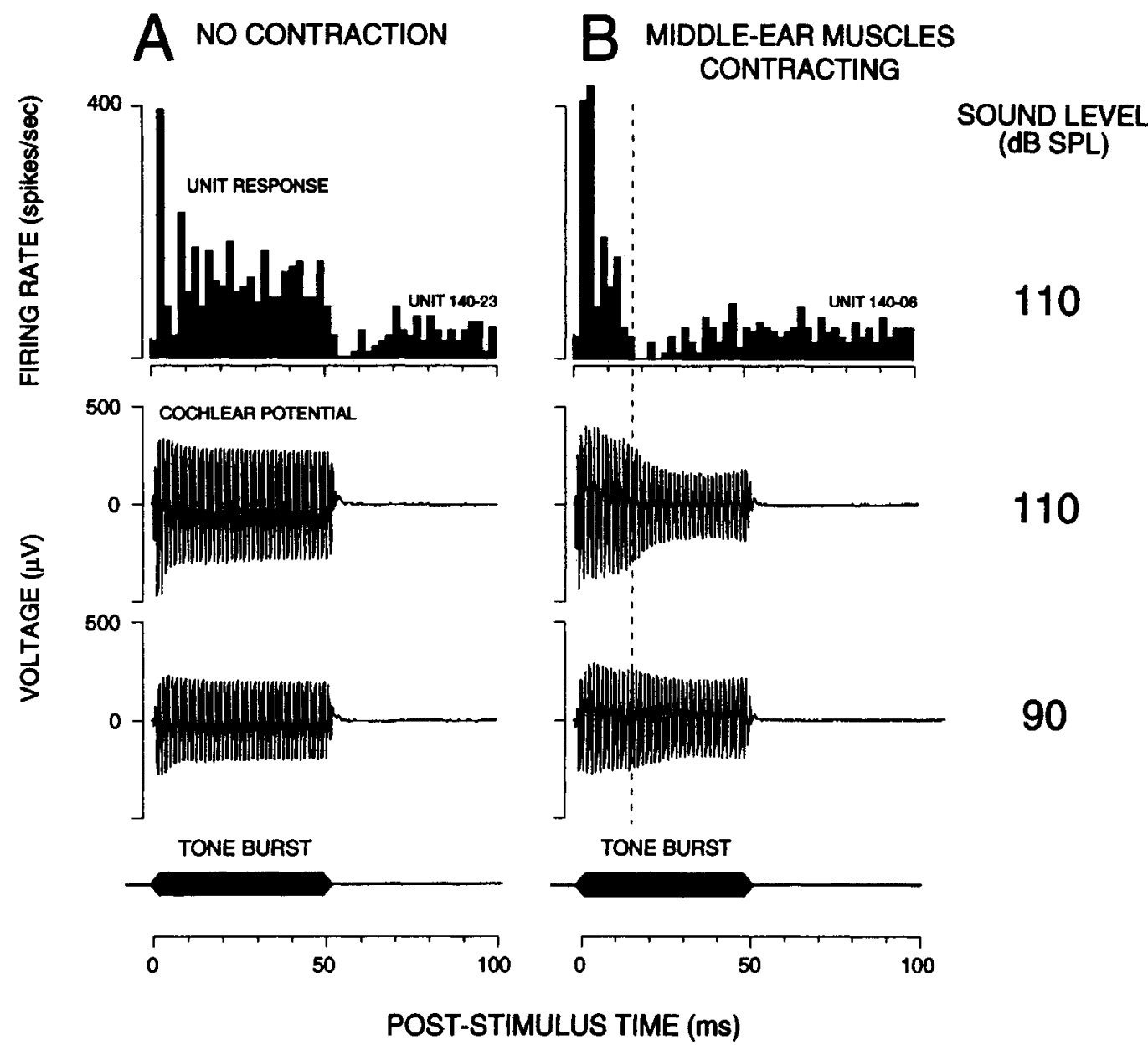

Figure 12. Effect of middle-ear muscle (MEM) contractions on the acoustic responsiveness of vestibular neurons. The top panel in $A$ shows a PST histogram with the typical (continuous) response of ARID units during $50 \mathrm{msec}$ long tone bursts in the absence of an acoustic MEM reflex. In $B$ the PST histogram shows the response pattern observed in one of three consecutive ARID units recorded while the acoustic MEM reflex was active. Bottom panels show the cochlear response potentials produced by $800 \mathrm{~Hz}$ tone burst stimulation at two sound levels. The sharp reduction in middle-ear transmission caused by MEM contraction is shown beginning at $15 \mathrm{msec}(\boldsymbol{B}$, dashed line).

1983; Colebatch and Halmagyi, 1992). For example, soundevoked potentials have been recorded from the guinea pig labyrinth after the chemical elimination of cochlear hair cells with aminoglycosides (Aran et al., 1979; Cazals et al., 1979, 1980, 1982), and some indirect evidence implicates the saccule as the generator for these potentials (Cazals et al., 1983; Didier and Cazals, 1989). The applicability of these findings to normal mammals has previously been questionable in light of the unknown effects of the chemical treatment on the surviving hair cells.

Several studies in humans have provided evidence that some sound-evoked neck reflexes are mediated by the sacculc (Townsend and Cody, 1971; Colebatch and Halmagyi, 1992). These studies are consistent with, and provide additional evidence for, the hypothesis that saccular afferents have a direct role in auditory behavior in mammals with normal cochleas.

The most comparable study to the present work (Young et al., 1977) examined the response sensitivity of vestibular afferents to both sound and vibration in all five vestibular end organs of the squirrel monkey. The general conclusion of this study was that the mammalian vestibular apparatus was poorly sensitive to sound, and that the saccule was only slightly more acoustically sensitive than other vestibular end organs. Because of their broad approach, these investigators reported the acoustic response thresholds of only seven saccular units and found a median threshold for rate change of $>120 \mathrm{~dB}$ SPL. No division of units was made based on the regularity of their discharges. Young et al. (1977) did separate saccular fibers by their synchronization phase to intense low-frequency tones, and the phase was found to correlate strongly with morphological polarization as determined by fiber responsiveness to head tilt (Young et al., 1977). This finding supports the interpretation that our PUSH and PULL fibers originate from saccular hair cells with opposite morphological polarizations. Interestingly, one fiber in the study (from the saccule) showed a phase-locking threshold of $76 \mathrm{~dB}$ SPL, but this unit was not described in detail, possibly because it was not held long enough to be studied thoroughly (Young et al., 1977). This saccular afferent from the squirrel monkey may be similar to the afferents studied here.

\section{Central projections of saccular afferents}

The possibility that the saccule is involved in some sort of auditory processing has been strengthened by recent demonstrations that saccular afferents send projections into the auditory brainstem (cochlear nucleus) in mammals (Burian and Gstoettner, 1988; Kevetter and Perachio, 1989). In the guinea 


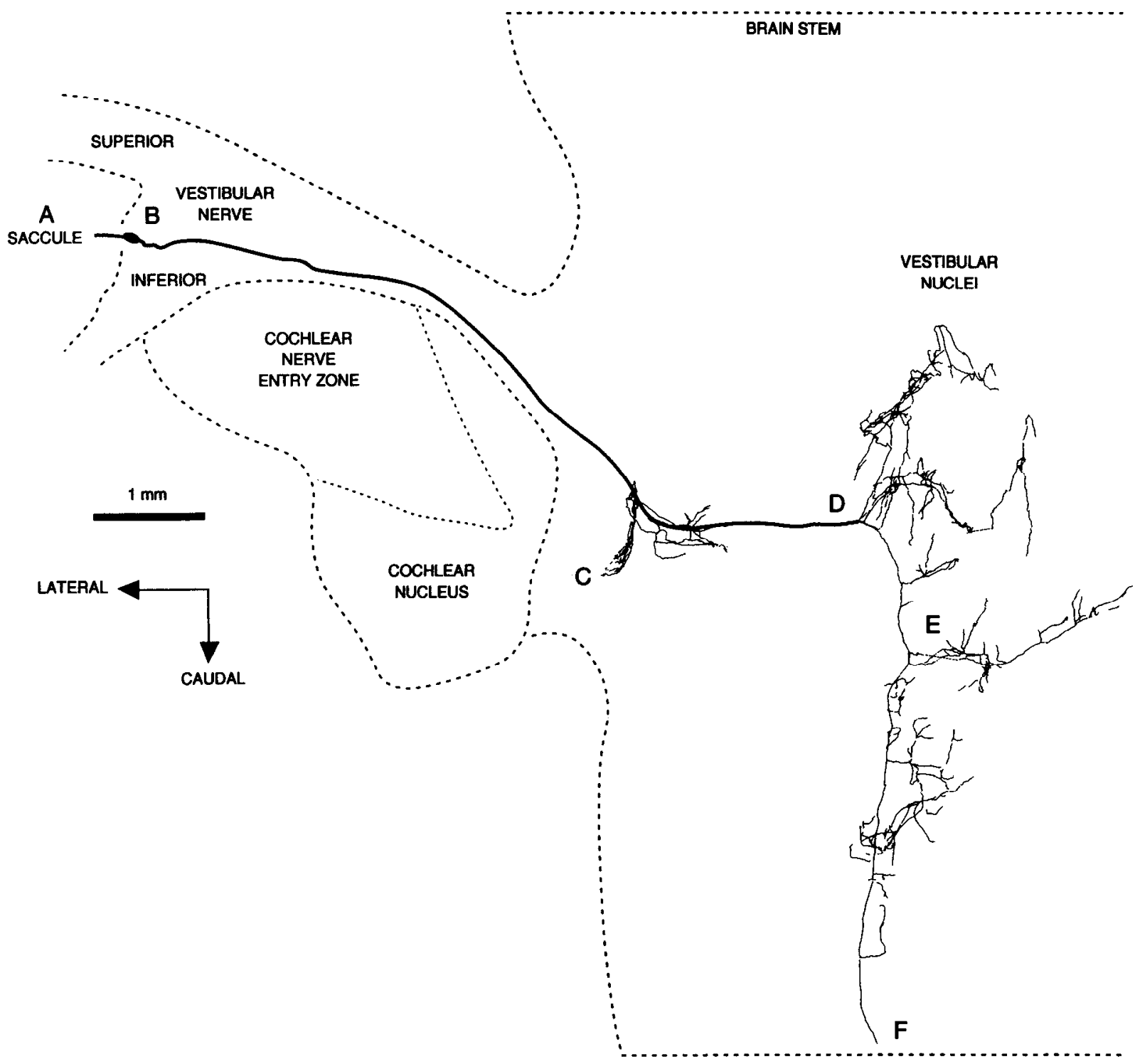

Figure 13. Reconstruction of an intracellularly labeled ARID unit showing its peripheral projection to the saccule $(A)$, its cell body $(B)$, and its central projections to the brainstem $(C-F)$. Neural processes were traced from near horizontal sections using a camera lucida (10 0 , $0.45 \mathrm{NA}$ objective). Two cells were intentionally labeled in this case and could be separated based on marked differences in labeling intensity. The lightly labeled fiber faded out just prior to the bifurcation of the dark fiber in the vestibular nuclei $(D)$ and therefore was not reconstructed. Presumed connectivity is indicated by dashed lines (e.g., $E$ ), which represent sections lost during histological processing. The fiber was not completely reconstructed because it extended beyond the caudal edge of the tissue block $(F)$. The boundary of the cochlear nucleus was estimated from lowpower tracings in the three sections containing the nearby neural arborization $(C)$. The fiber is shown collapsed along its dorsal-ventral dimension $(4.32 \mathrm{~mm})$ as are the partially schematized brainstem and nerve boundaries. Differences in line thickness represent fiber thickness to some extent and do not represent differences in labeling intensity.

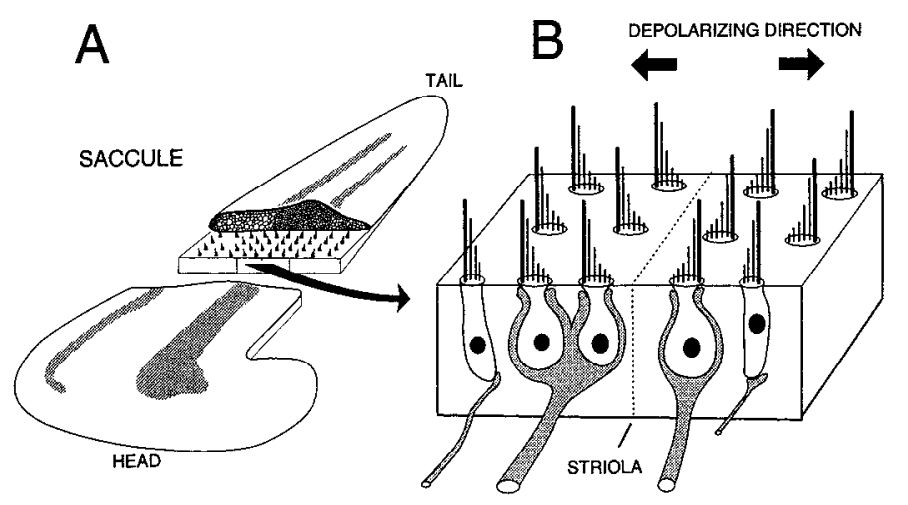

pig, $40 \%$ of irregularly discharging saccular afferents had cochlear nucleus projections (Kevetter and Perachio, 1989). These demonstrations reinforce the anatomical link between cochlear and vestibular systems established by the observation that some

Figure 14. Schematic representation showing the general shape of the mammalian saccular sensory epithelium $(A)$ and the morphological polarization of its hair cells $(B)$. Saccular hair cells are divisible into two classes that are morphologically polarized in opposite directions with a boundary along the longitudinal axis (striola) of the macula. Flaskshaped type I hair cells with chalice-like afferent endings predominate near the striola $(B)$. Some of these may exhibit variable directions of morphological polarization (not shown). Figure adapted from Lindeman (1973). 
cochlear efferent neurons collateralize within the vestibular nuclei (Rasmussen, 1960; Brown et al., 1988).

We were unable to demonstrate cochlear nucleus projections from ARID afferents, although this negative result may be readily accounted for by the paucity of well-labeled ARID fibers. We did, however, find an elaborate collateral that terminated on cell bodies in a nondescript region near the ventromedial border of the cochlear nucleus (Fig. 13C). This region is contiguous with the outflow fibers of the ventral acoustic stria (trapezoid body), and the properties of its constituent neurons are unknown. It may represent a previously undefined region for the processing of auditory information.

With appropriate central connections, ARID units could serve a number of different auditory functions, the principal categories being behavior and sensation. Potential acoustic behaviors are plentiful. Saccular afferents are known to make oligosynaptic connections with numerous cranial and cervical motoneurons (Hwang and Poon, 1975; Wilson et al., 1977). Furthermore, sounds at levels that trigger ARID units also produce rapid activation of motoneurons supplying the eye muscles (Galambos et al., 1953), neck muscles (Townsend and Cody, 1971; Colebatch and Halmagyi, 1992), and MEMs (Guinan and McCue, 1987). The relationship between ARID afferents and MEM motoneurons is particularly intriguing, since both classes of neurons have best frequencies near $1000 \mathrm{~Hz}$ and thresholds $>90 \mathrm{~dB}$ SPL (Guinan and McCue, 1987; Kobler et al., 1992). The primary afferents for the acoustic MEM reflexes have long been assumed to arise solely in the cochlea (Borg, 1973), but the primary afferents and interneurons remain unknown (Joseph et al., 1985; Rouiller et al., 1989). All available anatomical evidence on the pathway of the acoustic MEM reflex is consistent with contributions from ARID afferents (Borg, 1973). However, we note that ARID afferents are unlikely to be solely responsible for acoustically evoked MEM contractions owing to an additional high-frequency response region exhibited by MEM motoneurons (Kobler et al., 1992) and absent in ARID units (McCue, 1993).

The possibilities for ARID vestibular afferent involvement in sensation are also numerous. Sound levels that trigger ARID afferents cause transitions to discomfort in the old (e.g., rock music) and pleasure in the young (e.g., rock music). If a saccularauditory pathway is present in humans, it even holds the remote possibility of facilitating treatment for profound sensorineural deafness. An electronic hearing prosthesis interfaced with the saccule ("saccular implant") might produce an interpretable sensation, perhaps comparable to the single-channel cochlear prosthesis (Kiang and Moxon, 1972) for patients lacking cochlear neurons. Much, of course, depends upon the current use and plasticity of central connections.

\section{References}

Aran J-M, Cazals Y, Erre J-P, Guilhaume A (1979) Conflicting electrophysiological and anatomical data from drug impaired guinea pig cochleas. Acta Otolaryngol (Stockh) 87:300-309.

Beentjes BIJ (1972) The cochlear aqueduct and the pressure of cerebrospinal and endolabyrinthine fluids. Acta Otolaryngol (Stockh) 73: $112-120$.

Borg E (1973) On the neuronal organization of the acoustic middle ear reflex. A physiological and anatomical study. Brain Res 49:101123.

Borg E, Møller AR (1975) Effect of central depressants on the acoustic middle ear reflex in rabbit. Acta Physiol Scand 94:327-338.

Brown MC, Liberman MC, Benson TE, Ryugo DK (1988) Brainstem branches from olivocochlear axons in cats and rodents. J Comp Neurol 278:591-603.

Burian M, Gstoettner W (1988) Projection of primary vestibular afferent fibres to the cochlear nucleus in the guinea pig. Neurosci Lett 84:13-17.

Cazals Y, Aran J-M, Erre J-P, Guilhaume A, Hawkins JE Jr (1979) "Neural" responses to acoustic stimulation after destruction of cochlear hair cells. Arch Otorhinolaryngol 224:61-70.

Cazals Y, Aran J-M, Erre J-P, Guilhaume A (1980) Acoustic responses after total destruction of the cochlear receptor: brainstem and auditory cortex. Science 210:83-86.

Cazals Y, Aran J-M, Erre J-P (1982) Frequency sensitivity and selectivity of acoustically evoked potentials after complete cochlear hair cell destruction. Brain Res 231:197-203.

Cazals Y, Aran J-M, Erre J-P, Guilhaume A, Aurousseau C (1983) Vestibular acoustic reception in the guinea pig: a saccular function? Acta Otolaryngol (Stockh) 95:211-217.

Colebatch JG, Halmagyi GM (1992) Vestibular evoked potentials in human neck muscles before and after unilateral vestibular deafferentation. Neurology 42:1635-1636.

Didier A, Cazals Y (1989) Acoustic responses recorded from the saccular bundle on the eighth nerve of the guinea pig. Hear Res 37:123128.

Fernández C, Goldberg JM (1976a) Physiology of peripheral neurons innervating otolith organs of the squirrel monkey. I. Response to static tilts and long-duration centrifugal force. J Neurophysiol 39:970-984.

Fernández C, Goldberg JM (1976b) Physiology of peripheral neurons innervating otolith organs of the squirrel monkey. II. Directional selectivity and force-response relations. J Neurophysiol 39:985-995.

Fernández C, Goldberg JM (1976c) Physiology of peripheral neurons innervating otolith organs of the squirrel monkey. III. Response dynamics. J Neurophysiol 39:996-1008.

Gacek RR, Rasmussen GL (1961) Fiber analysis of the statoacoustic nerve of guinea pig, cat, and monkey. Anat Rec 139:455-463.

Galambos R, Rosenberg PE, Glorig A (1953) The eyeblink response as a test for hearing. J Speech IIear Disord 18:373-378.

Gifford ML, Guinan JJ Jr (1983) Effects of crossed-olivocochlearbundle stimulation on cat auditory nerve fiber responses to tones. J Acoust Soc Am 74:115-123.

Gifford ML, Guinan JJ Jr (1987) Effects of electrical stimulation of medial olivocochlear neurons on ipsilateral and contralateral cochlear responses. Hear Res 29:179-194.

Goldberg J, Brown PB (1969) Response of binaural neurons of dog superior olivary complex to dichotic tonal stimuli: some physiological mechanisms of sound localization. J Neurophysiol 32:613-636.

Goldberg JM, Fernández C (1977) Conduction times and background discharge of vestibular afferents. Brain Res 122:545-550.

Guinan JJ Jr, Gifford ML (1988) Effects of electrical stimulation of efferent olivocochlear neurons on cat auditory-nerve fibers. I. Ratelevel functions. Hear Res 33:97-114.

Guinan JJ Jr, Li RY-S (1990) Signal processing in brainstem auditory neurons which receive giant endings (calyces of Held) in the medial nucleus of the trapezoid body of the cat. Hear Res 49:321-334.

Guinan JJ Jr, McCue MP (1987) Asymmetries in the acoustic reflexes of the cat stapedius muscle. Hear Res 26:1-10.

Horikawa K, Armstrong WE (1988) A versatile means of intracellular labeling: injection of biocytin and its detection with avidin conjugates. J Neurosci Methods 25:1-11.

Hwang JC, Poon WF (1975) An electrophysiological study of the sacculo-ocular pathways in cats. Jpn J Physiol 25:241-251.

Igarishi M, Kato Y (1975) Effect of different vestibular lesions upon body equilibrium function in squirrel monkeys. Acta Otolaryngol (Stockh) [Suppl] 330:91-99.

Johnson DH (1980) The relationship between spike rate and synchrony in responses of auditory-nerve fibers to single tones. J Acoust Soc Am 68:1115-1122.

Joseph MP, Guinan JJ Jr, Fullerton BC, Norris BE, Kiang NYS (1985) Number and distribution of stapedius motoneurons in cats. J Comp Neurol 232:43-54.

Kevetter GA, Perachio AA (1989) Projections from the sacculus to the cochlear nuclei in the Mongolian gerbil. Brain Behav Evol 34: 193-200.

Kiang NYS, Moxon EC (1972) Physiological considerations in artificial stimulation of the inner ear. Ann Otol Rhinol Laryngol 81:714731 . 
Kiang NYS, Watanabe T, Thomas EC, Clark LF (1965) MIT research monograph, Discharge patterns of single fibers in the cat's auditory nerve. Cambridge, MA: MIT Press.

Kobler JB, Guinan JJ Jr, Vacher SR, Norris BE (1992) Acoustic-reflex frequency selectivity in single stapedius motoneurons of the cat. $J$ Neurophysiol 68:807-817.

Lewis ER, Baird RA, Leverenz EL, Koyama H (1982) Inner ear: dye injection reveals peripheral origins of specific sensitivities. Science 215:1641-1643.

Liberman MC, Brown MC (1986) Physiology and anatomy of single olivocochlear neurons in the cat. Hear Res 24:17-36.

Liberman MC, Oliver ME (1984) Morphometry of intracellularly labeled neurons of the auditory nerve: correlations with functional properties. J Comp Neurol 223:163-176.

Lindeman HH (1973) Anatomy of the otolith organs. Adv Otorhinolaryngol 20:405-433.

Lowenstein O, Roberts TDM (1951) The localization and analysis of the responses to vibration from the isolated elasmobranch labyrinth. A contribution to the problem of the evolution of hearing in vertebrates. J Physiol (Lond) 114:471-489.

McCue MP (1993) Acoustic responses from primary vestibular neurons. $\mathrm{ScD}$ thesis, Massachusetts Institute of Technology.

McCue MP, Guinan JJ Jr (1993) Acoustic responses from primary afferent neurons of the mammalian sacculus. Assoc Res Otolaryngol Abstr 16:33.

Mikaelian D (1964) Vestibular response to sound: single unit recording from the vestibular nerve in fenestrated deaf mice (Df/Df). Acta Otolaryngol (Stockh) 58:409-422.

Moffat AJM, Capranica RR (1976) Auditory sensitivity of the saccule in the American toad (Bufo americanus). J Comp Physiol 105:1-8.

Popper AN, Fay RR (1973) Sound detection and processing by teleost fishes: a critical review. J Acoust Soc Am 53:1515-1529.

Rasmussen GL (1960) Efferent fibers of the cochlear nerve and cochlear nucleus. In: Neural mechanisms of the auditory and vestibular systems (Rasmussen GL, Windle W, eds), pp 105-115. Springfield, IL: Thomas.

Ribaric K, Bleeker JD, Wit HP (1992) Perception of audio-frequency vibrations by profoundly deaf subjects after fenestration of the vestibular system. Acta Otolaryngol (Stockh) 112:45-49.

Rouiller EM, Capt M, Dolivo M, De Ribaupierre F (1989) Neuronal organization of the stapedius reflex pathways in the rat: a retrograde HRP and viral transneuronal tracing study. Brain Res 476:21-28.

Ruggero MA, Rich NC (1987) Timing of spike initiation in cochlear afferents: dependence of site of innervation. J Neurophysiol 58:379403 .

Saidel WM, Popper AN (1983) The saccule may be the transducer for directional hearing of nonostariophysine teleosts. Exp Brain Res 50: 149-152.

Spoendlin H (1966) Ultrastructure of the vestibular sense organ. In: The vestibular system and its diseases (Wolfson RJ, ed), pp 39-68. Philadelphia: University of Pennsylvania.

Townsend GL, Cody DTR (1971) The averaged inion response evoked by acoustic stimulation: its relation to the saccule. Ann Otol Rhinol Laryngol 80:121-131.

Tullio P (1938) Démonstration des méthodes pour la stimulation acoustique des canaux semicirculaire. Acta Otolaryngol (Stockh) 26: 267.

Ver IL, Brown RM, Kiang NYS (1975) Low-noise chambers for auditory research. J Acoust Soc Am 58:392-398.

Walsh BT, Miller JB, Gacek RR, Kiang NYS (1972) Spontaneous activity in the eighth cranial nerve of the cat. Int J Neurosci 3:221235.

Wersäll J, Flock $\AA$, Ludquist P-G (1965) Structural basis for directional sensitivity in cochlear and vestibular sensory receptors. Cold Spring Harb Symp Quant Biol 30:115-132.

Wilson VJ, Gacek RR, Maeda M, Uchino Y (1977) Saccular and utricular input to cat neck motoneurons. J Neurophysiol 40:63-73.

Wit HP, Bleeker JD, Mulder HH (1984) Response of pigeon vestibular nerve fibers to sound and vibration with audiofrequencies. J Acoust Soc Am 75:202-208.

Young ED, Fernández C, Goldberg JM (1977) Responses of squirrel monkey vestibular neurons to audio-frequency sound and head vibration. Acta Otolaryngol (Stockh) 84:352-360. 